\title{
Intragenic transcription of a noncoding RNA modulates expression of $A S P 3$ in budding yeast
}

\author{
YU-CHING HUANG, ${ }^{1}$ HUNG-TA CHEN, ${ }^{2}$ and SHU-CHUN TENG ${ }^{1}$ \\ ${ }^{1}$ Department of Microbiology, College of Medicine, National Taiwan University, Taipei 10051, Taiwan \\ ${ }^{2}$ Institute of Molecular Biology, Academia Sinica, Taipei 11529, Taiwan
}

\begin{abstract}
Inter- and intragenic noncoding transcription is widespread in eukaryotic genomes; however, the purpose of these types of transcription is still poorly understood. Here, we show that intragenic sense-oriented transcription within the budding yeast ASP3 coding region regulates a constitutively and immediately accessible promoter for the transcription of full-length ASP3. Expression of this short intragenic transcript is independent of GATA transcription factors, which are essential for the activation of full-length $A S P 3$, and independent of RNA polymerase II (RNAPII). Furthermore, we found that an intragenic control element is required for the expression of this noncoding RNA (ncRNA). Continuous expression of the short ncRNA maintains a high level of trimethylation of histone $\mathrm{H} 3$ at lysine $4(\mathrm{H} 3 \mathrm{~K} 4 \mathrm{me} 3)$ at the ASP3 promoter and makes this region more accessible for RNAPII to transcribe the fulllength $A S P 3$. Our results show for the first time that intragenic noncoding transcription promotes gene expression.
\end{abstract}

Keywords: noncoding RNA; intragenic transcript; chromatin remodeling; nitrogen starvation; ASP3

\section{INTRODUCTION}

Noncoding RNAs (ncRNAs) are widespread transcripts occurring from yeast to human, but their functions remain unclear (Kapranov et al. 2002; Rinn et al. 2003; Yelin et al. 2003; Cheng et al. 2005; Davis and Ares 2006; Neil et al. 2009). Recent findings in human, mouse, and Saccharomyces cerevisiae demonstrate that these ncRNAs play roles in the regulation of gene expression (Azzalin et al. 2007; Houseley et al. 2007; Rinn et al. 2007; Luke et al. 2008; Nagano et al. 2008; Pandey et al. 2008; Schoeftner and Blasco 2008). ncRNAs exhibit their functions through either the transcribed RNAs (Camblong et al. 2007; Martianov et al. 2007; Berretta et al. 2008; Nishizawa et al. 2008; Wang et al. 2008) or the action of transcription (Martens et al. 2004; Bird et al. 2006; Hongay et al. 2006; Uhler et al. 2007; Houseley et al. 2008; Hartzog and Martens 2009). Although ncRNAs are predominantly transcribed in the antisense orientation to repress sense transcripts through RNA-mediated transcriptional gene silencing (Hongay et al. 2006; Camblong et al. 2007, 2009; Berretta et al. 2008; Houseley et al. 2008), other

Reprint requests to: Shu-Chun Teng, Department of Microbiology, College of Medicine, National Taiwan University, No. 1, Sec. 1, Jen-Ai Road, Taipei 10051, Taiwan; e-mail: shuchunteng@ntu.edu.tw; fax: (886) 2-23915293.

Article published online ahead of print. Article and publication date are at http://www.rnajournal.org/cgi/doi/10.1261/rna.2177410. types of ncRNA-mediated gene regulation have been identified. ncRNAs can be transcribed upstream of a promoter in the sense orientation to repress the downstream gene expression by a transcriptional interference mechanism (Martens et al. 2004; Bird et al. 2006). Additionally, antisense ncRNAs can promote gene expression through a chromatin-remodeling mechanism (Uhler et al. 2007). However, different regulations and functions have mainly been revealed for ncRNAs that are transcribed from intergenic regions. Little is known about the functions of the numerous ncRNAs transcribed from intragenic regions.

Nitrogen regulation (nitrogen catabolite repression [NCR]) in S. cerevisiae has been shown to be controlled by GATA family transcription factors. Upon depletion of rich nitrogen sources (e.g., glutamine and ammonia), the NCR genes are activated by the GATA factors Gatlp and Gln3p (Mitchell and Magasanik 1984; Courchesne and Magasanik 1988; Stanbrough et al. 1995). In the presence of rich nitrogen sources, both GATA factors are phosphorylated by TOR kinase and are restricted to the cytoplasm through the interaction with Ure2p (Beck and Hall 1999; Cardenas et al. 1999; Hardwick et al. 1999).

Asparaginase II is a periplasmic enzyme in yeast, hydrolyzing both $\mathrm{D}$ - and $\mathrm{L}$-asparagine to aspartate and ammonium cation (Dunlop et al. 1978). ASP3, an NCR-regulated gene that encodes asparaginase II, comprises four identical copies located near a ribosomal DNA cluster region on chromosome 
XII and is activated in a nitrogen-limited environment (Dunlop et al. 1980; Kim et al. 1988). The GATA activators Gat $1 p$ and Gln3p are required for up-regulation of ASP3 (Oliveira et al. 1999, 2003; Scherens et al. 2006). A large-scale transcriptome study showed that yeast cells alter the structure of the $5^{\prime}$ untranslated region of mRNA to enhance gene expression in response to environmental changes (Law et al. 2005). This study also detected a short nc transcript within the open reading frame (ORF) of ASP3. So far, however, no investigation regarding the regulation and function of this ncRNA has been undertaken. Here we study the phenotypes and functions of this ncRNA. We show that the intragenic transcript of ASP3 is expressed in the sense orientation both under nitrogen-rich conditions and under nitrogen starvation. Expression of this transcript is not mediated by GATA transcription factors and independent of RNA polymerase II (RNAPII). This intragenic transcription facilitates transcriptional initiation of RNAPII at the ASP3 promoter, thus enhancing the expression of full-length ASP3.

\section{RESULTS}

\section{The intragenic transcript of $A S P 3$ is expressed under nitrogen starvation and under nitrogen-rich conditions}

In a previous study, $A S P 3$ has been shown to produce two transcripts with different $5^{\prime}$ termini: The short form of ASP3 was only detected under regular growth conditions, and the full-length transcript was only expressed when nitrogen was limited (Law et al. 2005). We analyzed the expression of both the short transcript and full-length transcript of ASP3 under different nitrogen conditions by Northern blotting. The short form of $A S P 3$, termed ncASP3, was detected in the presence of ammonium-containing medium and continuously expressed under nitrogen starvation for $5 \mathrm{~h}$ (Fig. 1A). We should note that the faster migrating band assigned to ncASP 3 was not detected in the asp $3 \Delta$ strain (see below), suggesting that the signal is indeed a variant transcript of $A S P 3$ and not due to a cross-hybridizing species. In contrast to the short transcript, full-length $A S P 3$ was only induced in the nitrogen-limiting medium, as previously reported (Kim et al. 1988). Its activation was strong within $1 \mathrm{~h}$ after nitrogen starvation and fluctuated somewhat afterward. Compared to the expression status of full-length $A S P 3$, the level of the short transcript remained essentially unchanged after nitrogen starvation for the indicated time points (Fig. 1A). These data indicate that the regulation of the short transcript is different from that of full-length ASP3.

\section{Transcription of full-length but not short-form ASP3 is dependent on GAT1 and GLN3}

Nitrogen-dependent ASP3 expression was suggested to be mediated by two GATA-type transcription factors, Gatlp

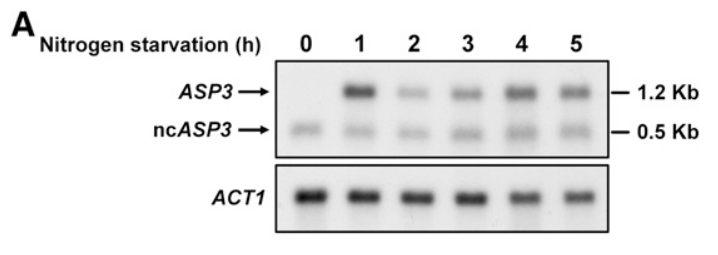

B

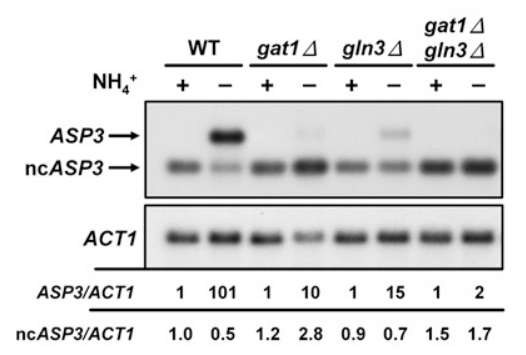

C

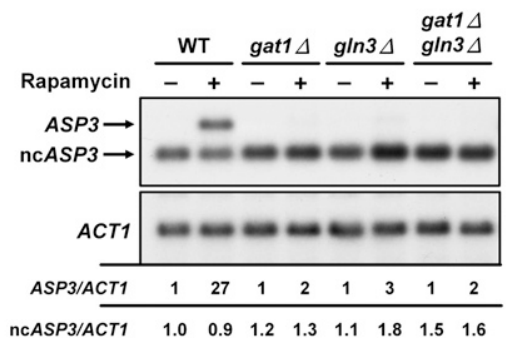

FIGURE 1. Intragenic transcription from the ASP3 ORF is detected in both ammonium-containing medium and under nitrogen starvation. (A) The wild-type strain was pre-grown in ammonium-containing medium. Cells were then washed with phosphate buffer and transferred to a $3 \%$ glucose solution for nitrogen starvation for $2 \mathrm{~h}$. Northern analysis of the two different transcripts of $A S P 3$ was conducted using an $A S P 3$ probe. The blot was subsequently probed against $A C T 1$ as a loading control. The sizes of transcripts are labeled at right. $(B, C)$ Intragenic transcription is independent of GAT1 and GLN3. (B) The wildtype, gat $1 \Delta, g \ln 3 \Delta$, and gat $1 \Delta \operatorname{gln} 3 \Delta$ mutant strains were treated as described in $A$, and then analyzed by Northern blotting. (C) Strains described in $B$ were pre-grown in ammonium-containing medium, treated with rapamycin, and then analyzed by Northern blotting. In $B$ and $C, A S P 3$ and ncASP3 signals were normalized to ACT1 signals. Values are displayed below the blots.

and Gln3p, which are restricted to the cytoplasm by Ure2pmediated recruitment in the presence of rich nitrogen sources (Beck and Hall 1999; Oliveira et al. 2003). With the addition of rapamycin, which inhibits TOR kinase activity and mimics nitrogen starvation conditions, the NCR-related genes are activated by both Gatlp and Gln3p (Beck and Hall 1999; Cardenas et al. 1999; Hardwick et al. 1999; Bertram et al. 2000). To test whether the short form of ASP3 is also regulated by the nitrogen regulatory mechanism, the expression of ASP3 in wild-type, gat $1 \Delta, g \ln 3 \Delta$, and gat $1 \Delta \operatorname{gln} 3 \Delta$ strains was determined by Northern analysis in ammoniumcontaining medium and under nitrogen starvation conditions. As shown in Figure 1B, expression of full-length ASP3 was significantly decreased in gat $1 \Delta$ and $g \ln 3 \Delta$ strains and almost abolished in the gat $1 \Delta$ gln $3 \Delta$ double deletion strain. These data agree with previous studies reporting the 
requirement of Gat $1 p$ and Gln3p for full-length $A S P 3$ gene activation after nitrogen starvation (Oliveira et al. 2003; Scherens et al. 2006). Analogous regulatory mechanisms for full-length ASP3 expression were observed in cells treated with rapamycin, which induces a condition mimicking nitrogen starvation (Fig. 1C). In contrast to transcription of full-length $A S P 3$, expression of the short transcript was not significantly altered in GATA-deleted strains (Fig. 1B,C). These data reveal that the regulation of the short-form ASP3 is different from that of the full-length transcript and is independent of nitrogen availability.

\section{Intragenic transcription of nc $A S P 3$ is RNAPII-independent}

The $5^{\prime}$ terminus of the short transcript was identified to start $657 \mathrm{nt}$ downstream relative to the initiation codon of ASP3 under nitrogen-rich conditions (Law et al. 2005). To test whether the continuously expressed short transcript that we observed under nitrogen starvation (Fig. 1) is transcribed from the same position, we performed $5^{\prime}$ and $3^{\prime}$ RACE followed by sequencing analysis (Fig. 2). Under both nitrogen-rich and nitrogen-depleted conditions, the short transcripts were internally initiated at position +658 , while the full-length ASP3 had several transcription start sites in the ASP3 promoter region, with a dominant position at $-18 \mathrm{nt}$ (data not shown). DNA sequencing data from 3' RACE showed that the transcripts obtained under both conditions are polyadenylated to similar extents (Fig. 2). The RACE data furthermore indicated that the transcription start site but not the $3^{\prime}$-termination sequence contributes to the length of the short transcript. To examine whether the short transcript of $A S P 3$ is synthesized by RNAPII, RNA from a strain with a temperature-sensitive mutant (rpb1-1) of RPO21 (Nonet et al. 1987), which encodes the largest subunit of RNAPII, was subjected to Northern analysis (Fig. 3).

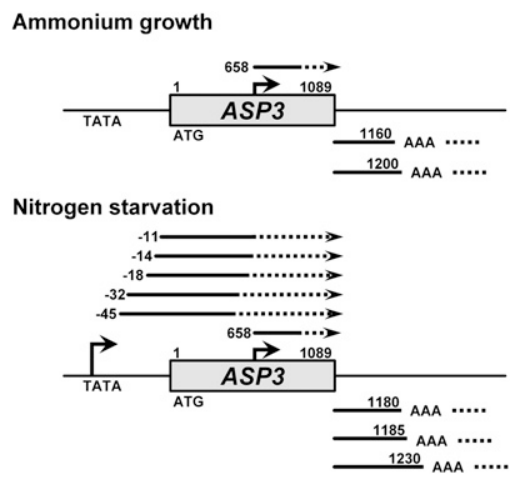

FIGURE 2. $5^{\prime}$ and $3^{\prime}$ RACE analyses of transcripts obtained in ammonium-containing medium or under nitrogen starvation. A schematic diagram shows the results of 5' (upper arrows) and 3' (lower bars) RACE from sequencing analyses. The intragenic transcript is initiated at position $658 \mathrm{nt}$ of the ASP 3 coding sequence and polyadenylated under both conditions.

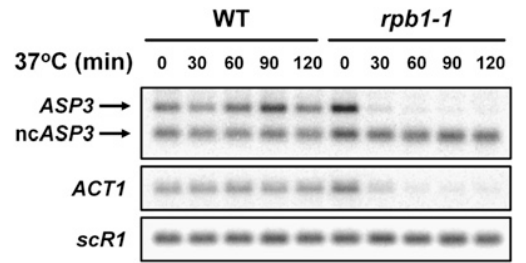

FIGURE 3. RNAPII-independent transcription of the short form of ASP3. Northern analysis of total RNA was performed under RNAPII inactivation. The $r p b 1 \Delta$ single copy-ASP3 cells containing either wildtype or $r p b 1-1$ mutant plasmid were pre-grown at $23^{\circ} \mathrm{C}$, and then shifted to $37^{\circ} \mathrm{C}$ for the indicated times. $A C T 1$ is an RNAPII-dependent transcript, and $s c R 1$ is an RNAPIII-dependent transcript.

When cells were shifted to non-permissive temperature, the full-length ASP3 mRNA was dramatically decreased, resembling the ACT1 mRNA control. However, unlike the decline of the ASP3 mRNA, the level of ncASP3 transcript was not affected when RNAPII was inactivated. The pattern of ncASP3 was similar to that of an RNAPIII-dependent transcript, $s c R 1$, which was also not affected in the $r p b 1-1$ mutant. These data demonstrate that transcription of the short form of ASP3 is RNAPII-independent. Given that there is no Kozak consensus sequence (Kozak 1987) in the $5^{\prime}$ region and many stop codons are located in the vicinity downstream from the first ATG, the short transcript should be an RNAPII-independent ncRNA from the ASP3 coding region.

\section{An intragenic control element regulates ncASP3 expression}

Our results showed that the short transcript of ASP3 is internally initiated in both ammonium-containing medium and under nitrogen starvation. To determine the promoter of ncASP3, we measured the $\beta$-galactosidase activity in the strains containing either empty plasmid or containing the plasmid with the ASP3(306-657) coding region upstream of the lac $Z$ reporter gene. For the latter strain, a fivefold increase in $\beta$-galactosidase activity was detected; this increase was not dependent on nitrogen availability (Fig. 4A). These data are consistent with the finding that expression of the short transcript is unaffected under conditions containing or lacking nitrogen nutrients (Fig. 1A). Next, to gain further insight into the regulatory mechanism underlying the formation of the short transcript, the ASP3 locus containing the ASP3 coding sequence together with 755-nt upstream and 500-nt downstream flanking sequences was cloned into a CEN plasmid and expressed under the control of its own promoter. This plasmid was transformed into the asp3 deletion strain in which all four copies of ASP3 have been removed. Northern analysis of the transformants showed that both ASP3 and the ncRNA signals disappeared in the asp3 3 strain, supporting the conclusion that the faster-migrating band was not a cross-hybridizing signal 
A

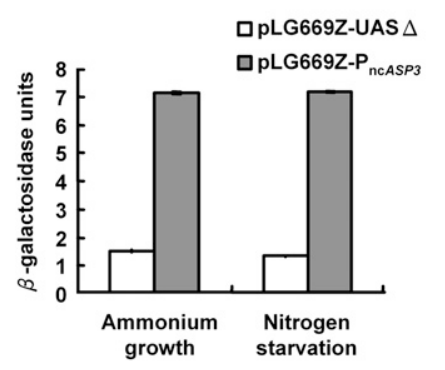

B

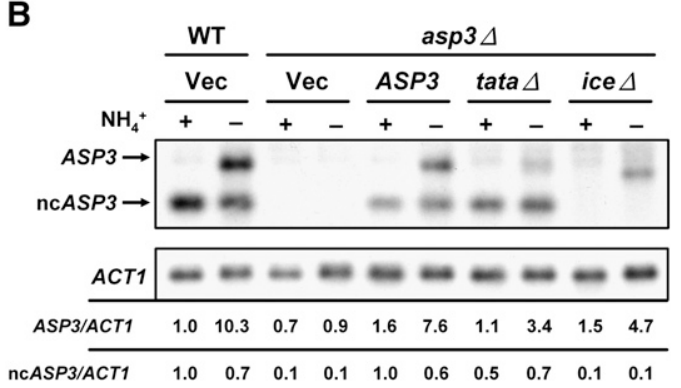

FIGURE 4. Expression of the short transcript is regulated by an intragenic control element but not the TATA element of ASP3. (A) Reporter assays of the wild-type strain with an empty vector (pLG669Z-UAS $\Delta$ ) or a plasmid containing the ASP3(306-657) coding

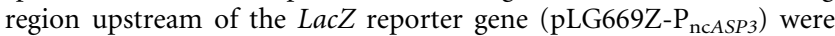
conducted under ammonium-containing or nitrogen starvation conditions. The $\beta$-galactosidase activities shown are means of three independent measurements. (B) Total RNAs were extracted from wild-type and asp3s mutant strains containing an empty vector $(\mathrm{Vec})$, wild-type (ASP3), TATA box-deleted (tata $\Delta)$, or intragenic control element-deleted (ice $\Delta$ ) expressing plasmid (pRS316 backbone) in ammonium-containing medium and under nitrogen starvation. The ASP 3 and ncASP3 signals determined by Northern blotting were normalized to ACT1 and are displayed below the blots.

(Fig. 4B). The expression levels of full-length and shortform ASP3 were slightly lower than those in the wild-type strain; however, the ratio of the two transcripts was preserved (Fig. 4B), indicating that transcription from this plasmid was regulated in the same way as that in the wildtype strain. To further define the control element for ncASP3, we tested two mutant plasmids: one containing a deletion of the putative TATA-box (tata $\Delta$, deletion from -112 to -91 nt relative to the ASP3 coding region), and the other containing a deletion of the potential intragenic control element (ICE) within the ASP3 gene (ice $\Delta$, deletion from 402 to $609 \mathrm{nt}$ ). Northern analysis showed that expression of full-length $A S P 3$ was considerably decreased in the tata $\Delta$ construct, while the expression of the short transcript remained unchanged (Fig. 4B), indicating that the regulation of the short transcript is different from that of full-length ASP3. However, transcription of ncASP3 was completely abolished in cells containing the ice $\Delta$ construct. Together, these data strongly suggest that there is a control element for ncASP3 located within the ASP 3 coding region and that the regulation of ICE is independent of nitrogen availability.

\section{Intragenic transcription mediates $A S P 3$ expression in cis}

Our data show that transcription of the short form of $A S P 3$ requires the ICE within the ASP3 coding sequence. To our surprise, without the expression of the short transcript, the transcription of full-length ASP3 was decreased to about two-thirds of the wild-type level in cells containing the ices construct (Fig. 4B). These data imply that either intragenic transcription or the control element within the coding region can promote full-length gene expression. Gene activation in cis mediated through a histone-remodeling mechanism by intergenic nc transcription was discovered previously (Uhler et al. 2007). To test whether such activation also exists intragenically, we engineered a strain containing a single chromosomal copy of $A S P 3$ and deleted the intragenic control element within ASP3 coding region (ice $\Delta$ ). In this strain, the short transcript was no longer detected, and the level of the full-length ASP3 was decreased by one-third under nitrogen starvation (Fig. 5A), similar to the result observed in the asp $3 \Delta$ strain containing the plasmid expressing asp3-ices (Fig. 4B). These data further confirmed the essential role of the ICE in intragenic transcription.

To address the question whether the short transcript can also act in trans to promote gene expression, we exogenously expressed the short form of ASP3 in a plasmid under the control of the $A D H 3$ promoter. Northern analysis revealed no significant alteration of full-length ASP3 expression in cells overexpressing the short transcript compared to that in the strain with the empty vector (Fig. 5B). These results
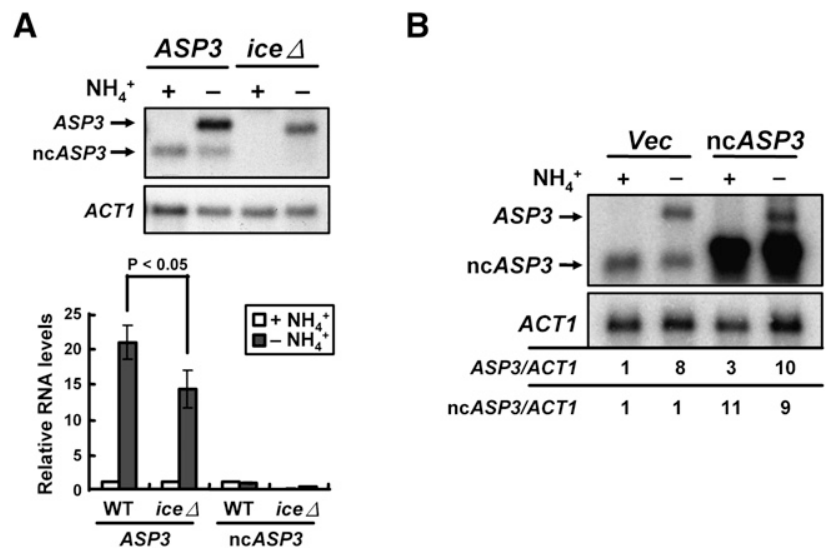

FIGURE 5. Intragenic transcription promotes full-length $A S P 3$ gene expression in cis but not in trans. $(A)$ Northern analysis of the single copy-ASP3 wild-type and ices strains in ammonium-containing medium and under nitrogen starvation. The ASP3 and ncASP3 signals were normalized to that of $A C T 1$ and are shown below as the average of three independent experiments. (B) Total RNAs were extracted from the wild-type strain containing the empty vector or ncASP3-expressing plasmid under the control of the $A D H 1$ promoter in ammoniumcontaining medium and under nitrogen starvation. Following Northern blotting, the ASP 3 and ncASP3 signals were normalized to the signal of $A C T 1$. Values are displayed below the blots. 
suggest that expression of full-length ASP3 is not promoted by the ncRNA itself, but by the action of transcription in cis.

\section{Disruption of the intragenic transcription hampers chromatin remodeling and transcriptional initiation of $A S P 3$}

Nucleosomes are composed of histone proteins and DNA, and the transcriptional activity of RNA polymerase on nucleosomes is correlated with the patterns of post-translational modification on histones (Strahl and Allis 2000; Iizuka and Smith 2003). Trimethylation of histone $\mathrm{H} 3$ at lysine $4(\mathrm{~K} 4)$ is found in the 5 ' region of transcribed genes and represents a hallmark of highly active genes (Santos-Rosa et al. 2002; Ng et al. 2003; Sims et al. 2003); this modification has been proposed to facilitate transcriptional elongation (Gerber and Shilatifard 2003). To determine the mechanism underlying the transcriptional modulation of full-length ASP3 expression, we performed chromatin immunoprecipitation (ChIP) and analyzed coprecipitated DNA by quantitative real-time PCR using primer pairs that amplify different regions of the ASP3 locus (Fig. 6A). Unlike the chromatin remodeling mechanism in which the nc transcript accelerated histone loss from the promoter region (Uhler et al. 2007), histone H3 eviction from the ASP3 promoter displayed no difference between wild-type and ice $\Delta$ strains after nitrogen starvation (Fig. 6B). To determine whether histone modification is altered in response to intragenic transcription, we used ChIP to determine the level of $\mathrm{H} 3 \mathrm{~K} 4 \mathrm{me} 3$ at the ASP3 locus using an antibody specific for H3K4me3. Surprisingly, H3K4me3 was present in the wild-type strain at the $5^{\prime}$ end of ASP3 under nitrogen-rich conditions and maintained at about the same level after nitrogen starvation for $60 \mathrm{~min}$ (Fig. 6C, left graph). In the ice $\Delta$ strain, the level of $\mathrm{H} 3 \mathrm{~K} 4 \mathrm{me} 3$ was not enriched in this region under nitrogen-rich conditions, yet it gradually increased to that of the wild type after nitrogen starvation for $60 \mathrm{~min}$. The enrichment of H3K4me3 was only detected in the promoter region of $A S P 3$ but not in the coding or the 3 ' downstream region (Fig. 6C). These data show that this histone modification, which is specifically enriched at active sites of transcription, was already present at the ASP3
B

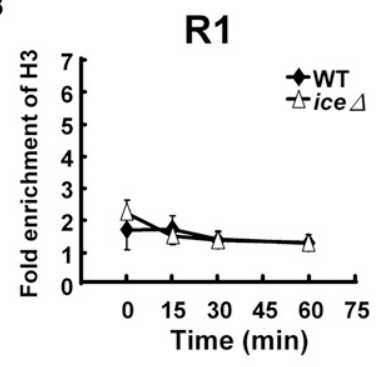

C
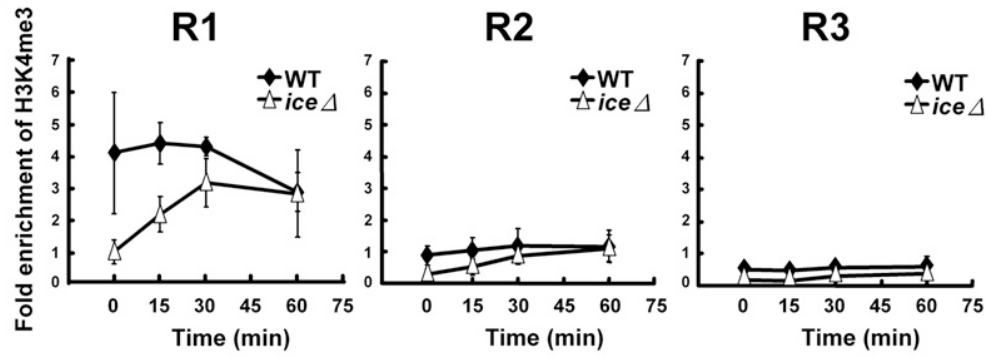

E

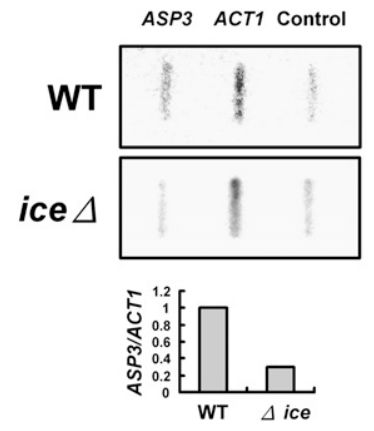

FIGURE 6. Disruption of the intragenic transcription hampers chromatin remodeling and transcriptional initiation of ASP3. (A) Schematic diagram of the ASP3 locus. The three regions used for PCR amplification in the ChIP assay are marked below. $(B-D)$ ChIP analyses performed at the ASP3 locus. Samples were collected at the indicated time points after nitrogen starvation. Regions 1-3 used for the PCR amplification are indicated. (B) ChIP analyses of histone H3 occupancy. (C) ChIP analyses of H3K4me3 at the ASP3 locus. (D) Rate of RNAPII-mediated initiation of transcription at the TATA-box of ASP3 was assayed by ChIP, using antibody against Ser5-phosphorylated CTD. Data are shown as relative levels compared to signals measured at time 0. (E) Nuclear run-on analysis was conducted to detect the transcription rate of ASP3 in the wild-type and ice $\Delta$ strains after nitrogen starvation. Fragments of ACT1 and the multiple cloning sites of the pBSKS plasmid were used as positive and negative controls, respectively. The ASP3 signals were normalized to that of ACT1 and are shown below.

promoter in the wild-type strain before nitrogen starvation. Similar observations were reported in mammalian genes activated by the transcription factor NF- $\kappa \mathrm{B}$ in response to inflammation. A subset of NF- $\mathrm{B}$ target genes that contained high levels of $\mathrm{H} 3 \mathrm{~K} 4 \mathrm{me} 3$ at promoter regions before stimulation was immediately transcribed upon activation (Saccani et al. 2001; Natoli 2009). Next, we used ChIP to investigate whether initiation of transcription by RNAPII at ASP3 is affected in the absence of the short transcript under nitrogen starvation. The carboxy-terminal domain (CTD) of RNAPII is phosphorylated at serine 5 upon 
initiation and phosphorylated at serine 2 during elongation (Komarnitsky et al. 2000). By using ChIP with specific antibodies against CTD serine 5P, we determined the efficiency of initiation of ASP3 transcription. Consistent with the predominant enrichment of $\mathrm{H} 3 \mathrm{~K} 4 \mathrm{me} 3$ in the promoter region of the wild-type strain, the phosphorylation of serine 5 within the RNAPII CTD occurred much faster in the wild-type strain at the ASP3 promoter than in the ice $\Delta$ strain after nitrogen starvation (Fig. 6D).

Elevated mRNA levels may be caused by an increased transcription rate and/or a reduced mRNA degradation rate. To examine whether the elevated level of full-length ASP3 mRNA in the wild-type strain resulted from an increase in the transcription rate, we performed nuclear run-on experiments. The nuclear run-on assay is often employed to specifically determine the activity of RNA polymerase complex on the DNA template. As shown in Figure 6E, while the signal of $A S P 3$ was readily detected in the wild-type strain, the signal in the ice $\Delta$ strain was reduced and barely visible. These data suggest that continuous transcription of the ncRNA from the intragenic region of ASP3 facilitates transcriptional initiation of RNAPII at the promoter region of ASP3. As a result, the rate of transcription is increased, leading to an accumulation of the full-length ASP3 mRNA. In summary, our results demonstrate that transcription from the intragenic coding region makes the upstream promoter region more accessible to RNAPII to transcribe the full-length ASP3. Furthermore, our data suggest that the intragenic transcription-regulated ASP3 expression occurs only in cis but not in trans.

\section{DISCUSSION}

Environmental changes have been shown to instigate alterations in the structure of the $5^{\prime}$ untranslated region of mRNA in cells, leading to changes in gene expression (Law et al. 2005). Here we demonstrate that the internal initiation of ncASP3 transcription occurs in both nitrogen-rich medium and under nitrogen starvation. Expression of this short transcript is independent of GATA-type transcription factors, which are necessary for full expression of NCRregulated genes, as we observed for the full-length ASP3. We also provide evidence showing that the short form of ASP3 is not synthesized by RNAPII. To gain insight into the roles of the short transcript, we identified an intragenic control element within the ASP3 coding region, which is necessary for the expression of this ncRNA. In the absence of intragenic transcription, expression of the full-length ASP3 and RNAPII recruitment to the promoter region were decreased; concomitantly, a lower $\mathrm{H} 3 \mathrm{~K} 4 \mathrm{me} 3$ histone occupancy at the ASP3 promoter was detected. Taken together, these findings suggest that the transcription of short RNA in cis maintains a more accessible promoter for the RNAPII recruitment and facilitates the full-length ASP3 expression.

Production of short RNA due to internally initiated transcription induced by changes in the cells' environment was previously reported. A short transcript inside the ORF of the PRY3 gene was detected after treating yeast cells with mating pheromone (Bickel and Morris 2006). Multiple elements within the PRY3 locus were determined that affect expression of both full-length and short transcripts. The pheromone-induced transcription factor Ste12p was found to bind to upstream elements at the $P R Y 3$ promoter, impeding full-length transcription and simultaneously inducing initiation of the short transcript. The daughterspecific transcription factor Ace2p is required for expression of both full-length and short transcripts, and its binding sites are found in the $P R Y 3$ promoter region. In addition, a putative TATA-box was discovered within the coding region for the short transcript. However, for transcription of $A S P 3$, apparently a different mechanism applies. Several potential binding sites for GATA-type transcription factors are present at the ASP3 promoter (Oliveira et al. 2003; Scherens et al. 2006). However, our results show that Gat1p and $\mathrm{Gln} 3 \mathrm{p}$ are only required for the expression of full-length ASP3 but not of the short nc transcript. Despite analyzing a series of deletion mutants by Northern blotting, we did not find a control element within the ASP3 promoter regulating the expression of the short transcript (data not shown). Instead, we discovered that deletion of a 208-nt sequence within the ASP3 coding region (+402 to +609 ) abolishes ncASP3 transcription. The deleted DNA region, which we define as the intragenic control element (ICE), contains two separate TATA-like sequences. However, mutations of these TATA-like sequences did not change ncASP3 transcription compared with that of the wild-type sequence (data not shown).

Genome-wide studies established the presence of numerous unannotated transcripts within the yeast genome (Davis and Ares 2006; Neil et al. 2009). Several recent studies revealed that transcription of ncRNAs plays certain functional roles. The effects of these transcripts could be repressive (Martens et al. 2004; Bird et al. 2006; Hongay et al. 2006; Camblong et al. 2007; Houseley et al. 2008) or stimulatory (Uhler et al. 2007) for transcription. The gene PHO5 represents the first example of transcriptional activation by a ncRNA: In this case, the transcription of an noncoding antisense RNA initiated at the $3^{\prime}$ end of the gene activates full-length PHO5 expression (Uhler et al. 2007). This antisense transcription promotes the recruitment of RNAPII through accelerating histone loss from the promoter region. Different from the regulation of $\mathrm{PHO5}$, we found that the ncRNA in ASP3 is transcribed within the coding region in the sense orientation. Furthermore, we provide evidence for a histone-remodeling mechanism in which full-length gene activation is mediated by $\mathrm{H} 3 \mathrm{~K} 4$ trimethylation. Such posttranslational modification was not observed in the activation of PHO5 (Uhler et al. 2007).

The efficient expression of necessary genes in response to environmental changes is an essential requisite of life. In mammalian cells, the transcription factor NF- $\kappa \mathrm{B}$ controls 
the induction of many inflammatory genes to cope with microbial infection. Two classes of NF- $\kappa \mathrm{B}$-regulated genes that possess different chromatin configurations and induction kinetics were identified. One class of genes contains high levels of $\mathrm{H} 3 \mathrm{~K} 4 \mathrm{me} 3$ before stimulation and provides NF- $\mathrm{BB}$ and RNAPII with constitutive and immediate access (Saccani et al. 2001; Natoli 2009). Here we discovered that a similar mechanism is present in yeast. Continuous transcription of the short form of ASP3 maintains $\mathrm{H} 3 \mathrm{~K} 4 \mathrm{me} 3$ in the promoter region even under nitrogen-rich conditions (Fig. 7). This covalent modification may facilitate the binding of chromatinremodeling ATPase to disrupt the nucleosomes (SantosRosa et al. 2003). Therefore, the promoter region is slightly "open" and more accessible for transcription. Upon nitrogen starvation, RNAPII is immediately recruited to the ASP3 promoter without requiring progressive chromatin remodeling to enhance accessibility. The rapid induction of fulllength ASP3 may therefore be of benefit to adapt to nutrient deficiency. In conclusion, our findings illustrate a different example of transcriptional regulation: Activation of gene expression is achieved by intragenic transcription, which leads to accelerated RNAPII recruitment through a chromatinremodeling mechanism.

\section{MATERIALS AND METHODS}

\section{Plasmids, yeast strains, and growth conditions}

To exogenously express ASP3, the ASP3 ORF along with 1000-bp upstream and 500-bp downstream flanking sequence was amplified by PCR from S. cerevisiae genomic DNA and subsequently

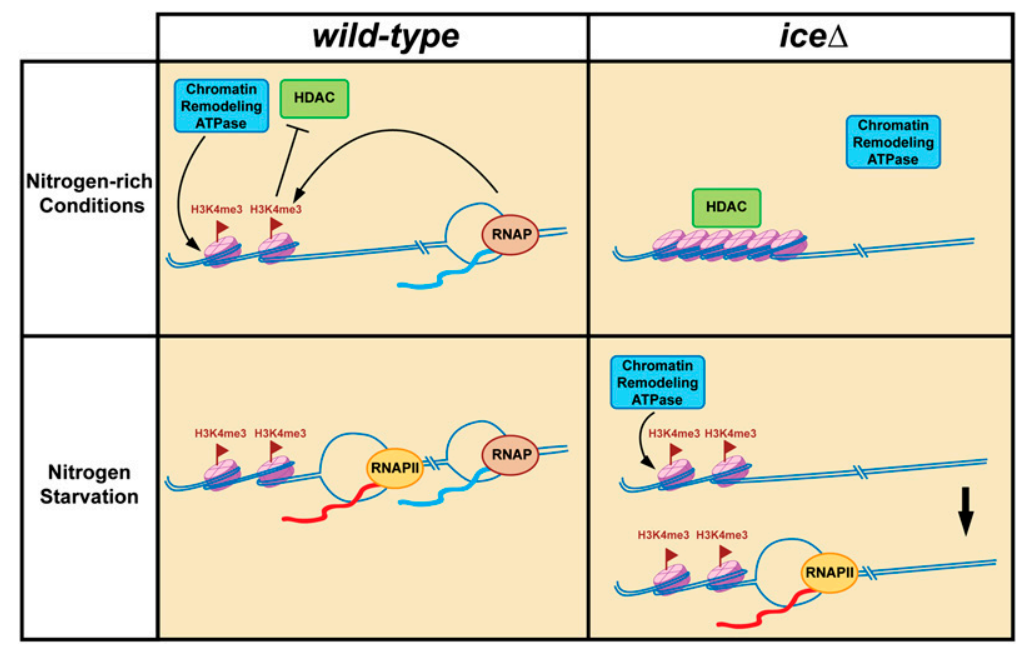

FIGURE 7. Model for the chromatin status at the ASP3 promoter in the presence and absence of intragenic transcription. The chromatin status in wild-type (left) and ice $\Delta$ (right) strains is shown under nitrogen-rich conditions (upper) and under nitrogen starvation (bottom). With the help of intragenic transcription (light-blue lines), the promoter region of ASP3 is immediately accessible for RNAPII upon nitrogen starvation. In the absence of intragenic transcription, the promoter region is more condensed, thus requiring chromatin-remodeling ATPase to enhance the accessibility of this region to RNAPII for ASP3 transcription (red lines) after nitrogen depletion. cloned into pGEMTeasy (Promega) to obtain pGEMTeasy-ASP3. The HindIII-SacII DNA fragment, which contains the 755-bp ASP3 promoter and 500-bp downstream sequence from pGEMTeasy-ASP3, was then subcloned into pRS316 to obtain pRS316ASP3. The XhoI-SacII DNA fragment from pRS316-ASP3 was further cloned into pRS306 to generate pRS306-ASP3. The pYM1 plasmid (Knop et al. 1999) was treated with BglII-Klenow-SacI to obtain KanMX6, and this fragment was then ligated with SacII-T4 polymerase-SacI-treated pRS306-ASP3 to obtain pRS306-ASP3KanMX6. pRS316-asp3(ices) and pRS306-asp3(ices)-KanMX6 plasmids were generated by using mutagenic PCR to delete the $A S P 3(385-625)$ DNA sequences in pRS316-ASP3 and pRS306ASP3-KanMX6, respectively. pRS316-asp3(tataA) was generated by using mutagenic PCR to delete nucleotide -129 to -76 of ASP3 in pRS316-ASP3. pRS315-rpb1-1 (expressing a temperaturesensitive Rpblp) was created by cloning the HindIII fragment from pRP1-1 (kindly provided by Richard Young [Massachusetts Institute of Technology]) into the same site of pRS315, and pRS315-RPB1 (expressing the wild-type Rpb1p) was generated by cloning the HindIII-Klenow-XbaI fragment from RY2049 (kindly provided by Richard Young) into the SalI-Klenow-XbaI-treated pRS315-rpb1-1. pLG669Z-UAS $\Delta$ was obtained by deletion of the XhoI fragment containing the upstream activation sites (UAS) of pLG669Z (Guarente and Ptashne 1981). The pLG669Z-P ncASP3 $_{3}$ plasmid used for the reporter assay was created by insertion of the ASP3(306-657) DNA fragment into pLG669Z-UAS $\Delta$. All primer sequences for PCR and mutagenesis are available upon request.

All yeast strains used in this study were isogenic to BY4743

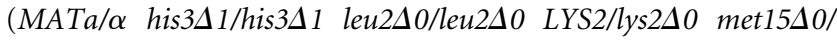

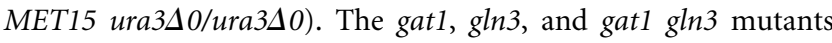
in the BY4741 background were obtained from the KanMX6deletion library (Invitrogen). There are four copies of ASP3 genes in the BY4741 strain. For simplification of the procedure, all four copies of ASP3 were deleted by double crossover of the ASP3 locus with an asp $3::$ KanMX6 fragment, which was PCR-amplified from the pYM1 plasmid, and selected for G418-resistant clones for the asp3 deletion mutant. Single-copy ASP3 wild-type and ice $\Delta$ strains were created by single crossover of the MluI-linearized pRS306-ASP3KanMX6 or pRS306-asp3(ices)-KanMX6 into the asp3::KanMX6 strain and selected for $\mathrm{Ura}^{+}$colonies. The wild-type and RPB1 temperature-sensitive mutant strains were created in the single-copy ASP3 BY4743 strain by deletion of one allele of RPB1 with HIS3MX6, transformation with pRS315-RPB1 or pRS315rpb1-1, and tetradissection to obtain $\mathrm{Ura}^{+}$, $\mathrm{Leu}^{+}$, and $\mathrm{His}^{+}$colonies.

Nitrogen starvation was performed for $2 \mathrm{~h}$ as previously described (Oliveira et al. 2003) unless indicated otherwise. Rapamycin treatment was conducted as described (Scherens et al. 2006) in synthetic complete medium with $2 \%$ glucose for $20 \mathrm{~min}$.

\section{RNA analysis}

For total RNA extraction, cells were grown to mid-log phase, harvested, lysed in $500 \mu \mathrm{L}$ 
of TRIzol solution (Invitrogen) with glass beads, and vigorously vortexed for $5 \mathrm{~min}$ at room temperature. The following manipulations were conducted as described by the manufacturer. For Northern analysis, $5 \mu \mathrm{g}$ of total RNA was separated on a $1.2 \%$ agarose gel containing 2.1\% formaldehyde in MOPS/formaldehyde buffer. RNA was transferred to a nylon membrane (PerkinElmer) and hybridized with $\left[\alpha-{ }^{32} \mathrm{P}\right] \mathrm{dCTP}$-labeled probes for the full-length and short forms of ASP3 and ACT1. scR1 was detected with oligonucleotide $5^{\prime}$-ATCCCGGCCGCCTCCATCAC-3' labeled with $\left[\gamma^{-32} \mathrm{P}\right]$ ATP using T4 polynucleotide kinase (NEB).

RACE analysis was performed by using the RACE cDNA Amplification Kit (Clontech). RNAs were prepared from ammonium-containing and nitrogen-starved cells. For sequencing of the RACE products, products were cloned into pGEMTeasy plasmid and then sequenced by SP6 or ASP3 primers.

\section{$\beta$-Galactosidase assays}

Cell pellets were collected from cells grown in ammoniumcontaining medium or grown under nitrogen starvation. Assays were performed as described (Guarente and Ptashne 1981) with chloroform and $0.1 \%$ SDS to permeabilize cells. One unit of $\beta$-galactosidase activity is defined as the optical density of product at $A_{420}$ per milliliter of culture at $A_{600}$ in a 30 -min assay. The values shown represent the means of three independent measurements.

\section{Chromatin immunoprecipitation (ChIP) analysis}

Yeast cells were grown overnight in $10 \mathrm{~mL}$ of synthetic medium with $2 \%$ glucose and refreshed in $200 \mathrm{~mL}$ of synthetic medium with $2 \%$ glucose until $A_{600}$ reached 0.5-0.8. An aliquot of $50 \mathrm{~mL}$ culture was collected and designated as time 0 , and the remaining culture was centrifuged for $1 \mathrm{~min}$ at $14,000 \mathrm{~g}$. Nitrogen starvation was performed for 15,30 , and $60 \mathrm{~min}$. All collected 50-mL cultures were fixed with $1 \%$ formaldehyde, and ChIP assay was performed as described (Ezhkova and Tansey 2006) using anti-H3 (ab1791; Abcam), antiH3K4me3 (9751; Cell Signaling), or anti-CTD-Ser5-P (05-623; Millipore) antibodies. DNA was analyzed by quantitative real-time PCR using PCR primers specific to the TATA-box, the intragenic region or to the downstream sequence of $A S P 3$. The control primers amplified an intergenic region of chromosome $\mathrm{V}$ that lacks any open reading frame (Komarnitsky et al. 2000). Results represent means from at least three independent experiments.

\section{Nuclear run-on analysis}

The nuclear run-on assay was performed as described (Elion and Warner 1986) with the following modifications. Cultures containing $5 \times 10^{7}$ cells were collected after nitrogen starvation for $1 \mathrm{~h}$. Cells were permeabilized in $0.5 \%$ of sodium $N$-lauroylsarcosine. Transcription was carried out for $30 \mathrm{~min}$ at $30^{\circ} \mathrm{C}$ in the presence of $100 \mu \mathrm{Ci}$ of $\left[\alpha-{ }^{32} \mathrm{P}\right] \mathrm{rUTP}$. Total RNAs were isolated, denatured for $5 \mathrm{~min}$ at $95^{\circ} \mathrm{C}$, and mixed with hybridization buffer. Membranes with immobilized DNAs were hybridized with labeled RNAs for $16 \mathrm{~h}$ at $60^{\circ} \mathrm{C}$. The DNA fragments corresponding to ASP3(1-347), ACT1(391-1108), and the multiple cloning region of pBSKS (Stratagene) were used as the probes.

\section{ACKNOWLEDGMENTS}

We thank Richard Young and Leonard Guarente for providing plasmids and Heiko Kuhn for manuscript editing. This work is supported by the National Science Council (NRPGM-98-3112B-002-039) and the National Health Research Institute of Taiwan (NHRI-EX98-9727BI) to S.-C.T.

Received March 16, 2010; accepted July 23, 2010.

\section{REFERENCES}

Azzalin CM, Reichenbach P, Khoriauli L, Giulotto E, Lingner J. 2007. Telomeric repeat containing RNA and RNA surveillance factors at mammalian chromosome ends. Science 318: 798-801.

Beck T, Hall MN. 1999. The TOR signalling pathway controls nuclear localization of nutrient-regulated transcription factors. Nature 402: 689-692.

Berretta J, Pinskaya M, Morillon A. 2008. A cryptic unstable transcript mediates transcriptional trans-silencing of the Tyl retrotransposon in S. cerevisiae. Genes Dev 22: 615-626.

Bertram PG, Choi JH, Carvalho J, Ai W, Zeng C, Chan TF, Zheng XF. 2000. Tripartite regulation of Gln $3 p$ by TOR, Ure2p, and phosphatases. J Biol Chem 275: 35727-35733.

Bickel KS, Morris DR. 2006. Role of the transcription activator Ste12p as a repressor of PRY3 expression. Mol Cell Biol 26: 7901-7912.

Bird AJ, Gordon M, Eide DJ, Winge DR. 2006. Repression of ADH1 and $A D H 3$ during zinc deficiency by Zap1-induced intergenic RNA transcripts. EMBO J 25: 5726-5734.

Camblong J, Iglesias N, Fickentscher C, Dieppois G, Stutz F. 2007. Antisense RNA stabilization induces transcriptional gene silencing via histone deacetylation in S. cerevisiae. Cell 131: 706-717.

Camblong J, Beyrouthy N, Guffanti E, Schlaepfer G, Steinmetz LM, Stutz F. 2009. Trans-acting antisense RNAs mediate transcriptional gene cosuppression in S. cerevisiae. Genes Dev 23: 15341545.

Cardenas ME, Cutler NS, Lorenz MC, Di Como CJ, Heitman J. 1999. The TOR signaling cascade regulates gene expression in response to nutrients. Genes Dev 13: 3271-3279.

Cheng J, Kapranov P, Drenkow J, Dike S, Brubaker S, Patel S, Long J, Stern D, Tammana H, Helt G, et al. 2005. Transcriptional maps of 10 human chromosomes at 5-nucleotide resolution. Science 308: $1149-1154$.

Courchesne WE, Magasanik B. 1988. Regulation of nitrogen assimilation in Saccharomyces cerevisiae: Roles of the URE2 and GLN3 genes. J Bacteriol 170: 708-713.

Davis CA, Ares M Jr. 2006. Accumulation of unstable promoterassociated transcripts upon loss of the nuclear exosome subunit Rrp6p in Saccharomyces cerevisiae. Proc Natl Acad Sci 103: 32623267.

Dunlop PC, Meyer GM, Ban D, Roon RJ. 1978. Characterization of two forms of asparaginase in Saccharomyces cerevisiae. J Biol Chem 253: 1297-1304.

Dunlop PC, Meyer GM, Roon RJ. 1980. Nitrogen catabolite repression of asparaginase II in Saccharomyces cerevisiae. J Bacteriol 143: 422-426.

Elion EA, Warner JR. 1986. An RNA polymerase I enhancer in Saccharomyces cerevisiae. Mol Cell Biol 6: 2089-2097.

Ezhkova E, Tansey WP. 2006. Chromatin immunoprecipitation to study protein-DNA interactions in budding yeast. Methods Mol Biol 313: 225-244.

Gerber M, Shilatifard A. 2003. Transcriptional elongation by RNA polymerase II and histone methylation. J Biol Chem 278: 2630326306.

Guarente L, Ptashne M. 1981. Fusion of Escherichia coli lacZ to the cytochrome $c$ gene of Saccharomyces cerevisiae. Proc Natl Acad Sci 78: 2199-2203.

Hardwick JS, Kuruvilla FG, Tong JK, Shamji AF, Schreiber SL. 1999. Rapamycin-modulated transcription defines the subset of nutrient-sensitive signaling pathways directly controlled by the Tor proteins. Proc Natl Acad Sci 96: 14866-14870. 
Hartzog GA, Martens JA. 2009. ncRNA transcription makes its mark. EMBO J 28: 1679-1680.

Hongay CF, Grisafi PL, Galitski T, Fink GR. 2006. Antisense transcription controls cell fate in Saccharomyces cerevisiae. Cell 127: 735-745.

Houseley J, Kotovic K, El Hage A, Tollervey D. 2007. Trf4 targets ncRNAs from telomeric and rDNA spacer regions and functions in rDNA copy number control. EMBO J 26: 4996-5006.

Houseley J, Rubbi L, Grunstein M, Tollervey D, Vogelauer M. 2008. A ncRNA modulates histone modification and mRNA induction in the yeast GAL gene cluster. Mol Cell 32: 685-695.

Iizuka M, Smith MM. 2003. Functional consequences of histone modifications. Curr Opin Genet Dev 13: 154-160.

Kapranov P, Cawley SE, Drenkow J, Bekiranov S, Strausberg RL, Fodor SP, Gingeras TR. 2002. Large-scale transcriptional activity in chromosomes 21 and 22. Science 296: 916-919.

Kim KW, Kamerud JQ, Livingston DM, Roon RJ. 1988. Asparaginase II of Saccharomyces cerevisiae. Characterization of the ASP3 gene. J Biol Chem 263: 11948-11953.

Knop M, Siegers K, Pereira G, Zachariae W, Winsor B, Nasmyth K, Schiebel E. 1999. Epitope tagging of yeast genes using a PCR-based strategy: more tags and improved practical routines. Yeast 15: 963972.

Komarnitsky P, Cho EJ, Buratowski S. 2000. Different phosphorylated forms of RNA polymerase II and associated mRNA processing factors during transcription. Genes Dev 14: 2452-2460.

Kozak M. 1987. An analysis of 5'-noncoding sequences from 699 vertebrate messenger RNAs. Nucleic Acids Res 15: 8125-8148.

Law GL, Bickel KS, MacKay VL, Morris DR. 2005. The undertranslated transcriptome reveals widespread translational silencing by alternative $5^{\prime}$ transcript leaders. Genome Biol 6: R111. doi: 10.1186/gb-2005-6-13-r111.

Luke B, Panza A, Redon S, Iglesias N, Li Z, Lingner J. 2008. The Ratlp $5^{\prime}$ to $3^{\prime}$ exonuclease degrades telomeric repeat-containing RNA and promotes telomere elongation in Saccharomyces cerevisiae. Mol Cell 32: 465-477.

Martens JA, Laprade L, Winston F. 2004. Intergenic transcription is required to repress the Saccharomyces cerevisiae SER3 gene. Nature 429: $571-574$.

Martianov I, Ramadass A, Serra Barros A, Chow N, Akoulitchev A. 2007. Repression of the human dihydrofolate reductase gene by a non-coding interfering transcript. Nature 445: 666-670.

Mitchell AP, Magasanik B. 1984. Regulation of glutamine-repressible gene products by the GLN3 function in Saccharomyces cerevisiae. Mol Cell Biol 4: 2758-2766.

Nagano T, Mitchell JA, Sanz LA, Pauler FM, Ferguson-Smith AC, Feil R, Fraser P. 2008. The Air noncoding RNA epigenetically silences transcription by targeting G9a to chromatin. Science 322: 17171720.

Natoli G. 2009. Control of NF-кB-dependent transcriptional responses by chromatin organization. Cold Spring Harb Perspect Biol 1: a000224. doi: 10.1101/cshperspect.a000224.

Neil H, Malabat C, d'Aubenton-Carafa Y, Xu Z, Steinmetz LM, Jacquier A. 2009. Widespread bidirectional promoters are the major source of cryptic transcripts in yeast. Nature 457: 10381042.

$\mathrm{Ng} \mathrm{HH}$, Robert F, Young RA, Struhl K. 2003. Targeted recruitment of Set 1 histone methylase by elongating Pol II provides a localized mark and memory of recent transcriptional activity. Mol Cell 11: 709-719.
Nishizawa M, Komai T, Katou Y, Shirahige K, Ito T, Toh EA. 2008. Nutrient-regulated antisense and intragenic RNAs modulate a signal transduction pathway in yeast. PLoS Biol 6: 2817-2830.

Nonet M, Scafe C, Sexton J, Young R. 1987. Eucaryotic RNA polymerase conditional mutant that rapidly ceases mRNA synthesis. Mol Cell Biol 7: 1602-1611.

Oliveira EM, Carvajal E, Bon EP. 1999. L-Asparaginase II of Saccharomyces cerevisiae. Activity profile during growth using an ure 2 mutant P40-3C and a P40-3C + Ure2p strain. Appl Biochem Biotechnol 77-79: 311-316.

Oliveira EM, Martins AS, Carvajal E, Bon EP. 2003. The role of the GATA factors Gln3p, Nillp, Dal80p and the Ure $2 p$ on ASP3 regulation in Saccharomyces cerevisiae. Yeast 20: 31-37.

Pandey RR, Mondal T, Mohammad F, Enroth S, Redrup L, Komorowski J, Nagano T, Mancini-Dinardo D, Kanduri C. 2008. Kcnqlot1 antisense noncoding RNA mediates lineage-specific transcriptional silencing through chromatin-level regulation. Mol Cell 32: 232 246.

Rinn JL, Euskirchen G, Bertone P, Martone R, Luscombe NM, Hartman S, Harrison PM, Nelson FK, Miller P, Gerstein M, et al. 2003. The transcriptional activity of human Chromosome 22. Genes Dev 17: 529-540.

Rinn JL, Kertesz M, Wang JK, Squazzo SL, Xu X, Brugmann SA, Goodnough LH, Helms JA, Farnham PJ, Segal E, et al. 2007. Functional demarcation of active and silent chromatin domains in human HOX loci by noncoding RNAs. Cell 129: 1311-1323.

Saccani S, Pantano S, Natoli G. 2001. Two waves of nuclear factor $\kappa B$ recruitment to target promoters. J Exp Med 193: 1351-1359.

Santos-Rosa H, Schneider R, Bannister AJ, Sherriff J, Bernstein BE, Emre NC, Schreiber SL, Mellor J, Kouzarides T. 2002. Active genes are tri-methylated at K4 of histone H3. Nature 419: 407-411.

Santos-Rosa H, Schneider R, Bernstein BE, Karabetsou N, Morillon A, Weise C, Schreiber SL, Mellor J, Kouzarides T. 2003. Methylation of histone $\mathrm{H} 3 \mathrm{~K} 4$ mediates association of the Isw1p ATPase with chromatin. Mol Cell 12: 1325-1332.

Scherens B, Feller A, Vierendeels F, Messenguy F, Dubois E. 2006. Identification of direct and indirect targets of the Gln3 and Gat1 activators by transcriptional profiling in response to nitrogen availability in the short and long term. FEM Yeast Res 6: 777-791.

Schoeftner S, Blasco MA. 2008. Developmentally regulated transcription of mammalian telomeres by DNA-dependent RNA polymerase II. Nat Cell Biol 10: 228-236.

Sims RJ III, Nishioka K, Reinberg D. 2003. Histone lysine methylation: A signature for chromatin function. Trends Genet 19: 629-639.

Stanbrough M, Rowen DW, Magasanik B. 1995. Role of the GATA factors Gln3p and Nillp of Saccharomyces cerevisiae in the expression of nitrogen-regulated genes. Proc Natl Acad Sci 92: 9450-9454.

Strahl BD, Allis CD. 2000. The language of covalent histone modifications. Nature 403: 41-45.

Uhler JP, Hertel C, Svejstrup JQ. 2007. A role for noncoding transcription in activation of the yeast PHO5 gene. Proc Natl Acad Sci 104: 8011-8016.

Wang X, Arai S, Song X, Reichart D, Du K, Pascual G, Tempst P, Rosenfeld MG, Glass CK, Kurokawa R. 2008. Induced ncRNAs allosterically modify RNA-binding proteins in cis to inhibit transcription. Nature 454: 126-130.

Yelin R, Dahary D, Sorek R, Levanon EY, Goldstein O, Shoshan A, Diber A, Biton S, Tamir Y, Khosravi R, et al. 2003. Widespread occurrence of antisense transcription in the human genome. Nat Biotechnol 21: 379-386. 

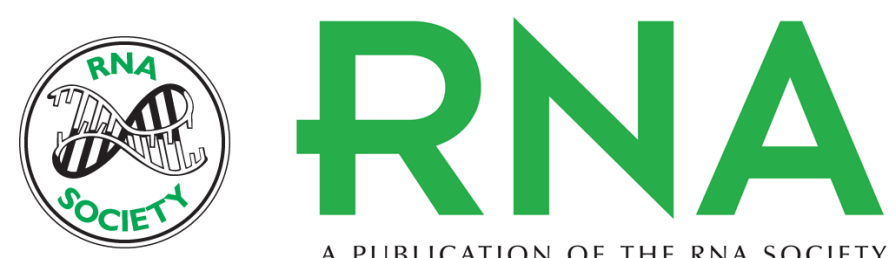

A PUBLICATION OF THE RNA SOCIETY

\section{Intragenic transcription of a noncoding RNA modulates expression of $A S P 3$ in budding yeast}

Yu-Ching Huang, Hung-Ta Chen and Shu-Chun Teng

RNA 2010 16: 2085-2093 originally published online September 3, 2010

Access the most recent version at doi:10.1261/rna.2177410

$\begin{array}{ll}\text { References } & \begin{array}{l}\text { This article cites } 56 \text { articles, } 26 \text { of which can be accessed free at: } \\ \text { http://rnajournal.cshlp.org/content/16/11/2085.full.html\#ref-list-1 }\end{array}\end{array}$

License

Email Alerting Receive free email alerts when new articles cite this article - sign up in the box at the Service top right corner of the article or click here.

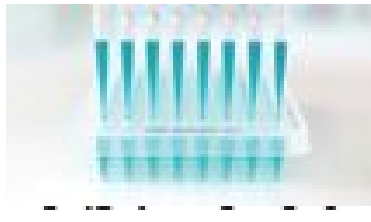

Providing Precise Solutions for your research.

To subscribe to RNA go to:

http://rnajournal.cshlp.org/subscriptions 